Check for updates

Cite this: RSC Adv., 2018, 8, 32325

Received 28th July 2018

Accepted 3rd September 2018

DOI: $10.1039 / c 8 r a 06357 e$

rsc.li/rsc-advances

\section{Chemical bond parameters, bond energy and the local crystal sites of $\mathrm{Eu}^{3+}$ in $\mathrm{Ca}_{5}\left(\mathrm{BO}_{3}\right)_{3} \mathrm{~F}: 1 \% \mathrm{Eu}^{3+}$ phosphor}

\author{
Yuhan Zhu, Yu Pan, Wenjun Wang, Haibing Xu, Liqun Zhou, Xiaoguang Liu* \\ and Ling Li iD *
}

The local crystal sites occupied by $\mathrm{Eu}^{3+}$ in $\mathrm{Ca}_{5}\left(\mathrm{BO}_{3}\right)_{3} \mathrm{~F}: 1 \% \mathrm{Eu}^{3+}$ phosphor were investigated experimentally and theoretically. $\mathrm{Ca}_{5}\left(\mathrm{BO}_{3}\right)_{3} \mathrm{~F}: 1 \% \mathrm{Eu}^{3+}$ was synthesized by high-temperature solid-state method in air. The crystal structure and optical properties of the phosphor were studied by X-ray powder diffraction and photoluminescence, respectively. Two different $\mathrm{O}^{2-} \rightarrow \mathrm{Eu}^{3+} \mathrm{CT}$ broad bands with the peaks at 266 and $283 \mathrm{~nm}$ in $\mathrm{Ca}_{5}\left(\mathrm{BO}_{3}\right)_{3} \mathrm{~F}: 1 \% \mathrm{Eu}^{3+}$ were detected, indicating the $\mathrm{Eu}^{3+}$ sites occupied $\mathrm{Ca} 2$ and $\mathrm{Ca} 1$, respectively. The different sharp $\mathrm{f}-\mathrm{f}$ emission spectra under the excitation of 283 and $266 \mathrm{~nm}$ proved that there are two different local lattice environments around $\mathrm{Eu}^{3+}$ existing in $\mathrm{Ca}_{5}\left(\mathrm{BO}_{3}\right)_{3} \mathrm{~F}: 1 \% \mathrm{Eu}^{3+}$. Environmental factor $h_{\mathrm{e}}$, the standard deviation of environmental factor (EFSD) $\sigma\left(h_{\mathrm{e}_{i}}\right)$ and the bond energy were used to illustrate and explain the site occupancy mechanism of $\mathrm{Eu}^{3+}$ into the host lattice. By comparing the intensity ratios of ${ }^{5} \mathrm{D}_{0} \rightarrow{ }^{7} \mathrm{~F}_{2}$ transition to the ${ }^{5} \mathrm{D}_{0} \rightarrow{ }^{7} \mathrm{~F}_{1}$ transition, $/\left({ }^{5} \mathrm{D}_{0} /{ }^{7} \mathrm{~F}_{2}\right) / /\left({ }^{5} \mathrm{D}_{0} /{ }^{7} \mathrm{~F}_{1}\right)$ of $\mathrm{Eu}^{3+}$ at $\mathrm{Ca} 2$ (7.381) was found to be 2.5 times stronger than that of $\mathrm{Eu}^{3+}$ at $\mathrm{Ca}$ site (2.933). $\sigma\left(h_{\mathrm{e}_{i}}\right)$ was calculated to analyze the $/\left({ }^{5} D_{0} /{ }^{7} F_{2}\right) / /\left({ }^{5} D_{0} /{ }^{7} F_{1}\right)$ value. On the basis of the bond valence model, a bondenergy method was used to study the occupancy of the Eu ion, which indicated that the preferential sites of Eu ion occupancy in the $\mathrm{Ca}_{5}\left(\mathrm{BO}_{3}\right)_{3} \mathrm{~F}$ are the $\mathrm{Ca} 2$ and $\mathrm{Ca} 1$ sites. All three theoretical calculation results are consistent with each other.

\section{Introduction}

White LEDs have the advantages of high brightness, low energy consumption, long life, small size, no radiation, no pollution, etc. It is considered the new generation of green light sources. The two commonly used methods for implementing white LEDs are: blu-ray chip and YAG: $\mathrm{Ce}^{3+}$ yellow phosphor combination, and near-ultraviolet LED chip combined with the trichromatic phosphor. However, the former lacks the red portion, resulting in a lower color rendering index (less than 80) and a higher color temperature (greater than 40), while the latter is less commercially available and lacks suitable red light materials. ${ }^{1-6}$ Therefore, finding a suitable red luminescent material and improving the color rendering index has become an important issue in the development of trichromatic white LEDs. In the rare earth family, $\mathrm{Eu}^{3+}$ ions are widely used in various fields of luminescent materials because they have good luminescence properties and can emit red fluorescence with good monochromaticity. ${ }^{7-9}$ The luminescence of $\mathrm{Eu}^{3+}$ derived from the $4 \mathrm{f}^{6}$ transition

Hubei Collaborative Innovation Center for Advanced Organochemical Materials, Ministry-of-Education Key Laboratory for the Synthesis and Applications of Organic Functional Molecules, Hubei University, Wuhan, Hubei, China. E-mail: liling402431@hotmail.com; liuxiaoguang402@hotmail.com consists of sharp peaks of the $\mathrm{Eu}^{3+}$-doped inorganic compound in the red region. ${ }^{\mathbf{1 0 - 1 2}}$

Rare earth ion-doped borate luminescent materials have high UV transparency, nonlinear characteristics, good stability and optical properties, and they are expected to become a promising fluorescent material, attracting more and more research worldwide. ${ }^{13-15}$ Among the nonlinear optical crystal materials that have been found, ultraviolet and deep ultraviolet nonlinear optical crystals that have excellent performance are almost all borate compounds. $\mathrm{Ca}_{5}\left(\mathrm{BO}_{3}\right)_{3} \mathrm{~F}$ was first reported by Lei et al. in 1989. The crystal was also a new type of nonlinear optical crystal. The powder doubling effect was measured to be 2-3 KDP, and the transmission range was $190-3600 \mathrm{~nm}^{\mathbf{1 6 , 1 7}}$ There are many published papers focusing on energy transfer and color-tunability of rare earth (e.g., $\left.\mathrm{Bi}^{3+}, \mathrm{Ce}^{3+}, \mathrm{Tb}^{3+}\right)$-doped $\mathrm{Ca}_{5}\left(\mathrm{BO}_{3}\right)_{3} \mathrm{~F}^{18,19}$ There are three kinds of octahedrons surrounding the $\mathrm{Ca}$ ions that could be substituted by $\mathrm{Eu}^{3+}$. They have different covalence, average bond lengths, central ion coordination numbers, and charges of ligands in chemical bonds. These result in $\mathrm{Eu}^{3+}$ ions with different photoluminescence properties. For the above reasons, $\mathrm{Ca}_{5}\left(\mathrm{BO}_{3}\right)_{3} \mathrm{~F}$ compound with $\mathrm{Ca}^{2+}$ and $\mathrm{B}^{3+}$ cationic sites can be selected as a host lattice, and $\mathrm{Eu}^{3+}$ ions are used as a good activator. However, studies on the effects of $\mathrm{Eu}^{3+}$ on the CT properties and 
the local crystal sites occupied by $\mathrm{Eu}^{3+}$ in $\mathrm{Ca}_{5}\left(\mathrm{BO}_{3}\right)_{3} \mathrm{~F}: 1 \% \mathrm{Eu}^{3+}$ phosphor are rarely reported.

The environmental factor $\left(h_{\mathrm{e}}\right)$ was used to investigate the sites of $\mathrm{Eu}^{3+}$ based on the relationship between the CT bands of $\mathrm{Eu}^{3+}$ and the crystal structure of the host lattice. $h_{\mathrm{e}}$ can be calculated using the complex crystal chemical bond theory. The smaller the $h_{\mathrm{e}}$, the larger the charge transfer energy from $\mathrm{O}^{2-}$ to $\mathrm{Eu}^{3+}$. Through the literature, we know that the PL intensity ratio between the ${ }^{5} \mathrm{D}_{0} \rightarrow{ }^{7} \mathrm{~F}_{2}$ and ${ }^{5} \mathrm{D}_{0} \rightarrow{ }^{7} \mathrm{~F}_{1}$ transition of $\mathrm{Eu}^{3+}$ increases as the crystal distortion increases. The degree of distortion was calculated by the environmental factor standard deviation (EFSD) $\sigma\left(h_{\mathrm{e}_{i}}\right)$. This can provide information on the Eu ion sites. At the same time, the bond energy theory can be used to discuss the site occupancy of dopants into the host. In previous papers, this method has been proven; for example, the site preferential occupancy for Eu in $\mathrm{Sr}_{2} \mathrm{~V}_{2} \mathrm{O}_{7}, \mathrm{Sr}_{9} \mathrm{Gd}\left(\mathrm{VO}_{4}\right)_{7}$ and $\mathrm{Sr}_{2} \mathrm{~V}_{2} \mathrm{O}_{7} / \mathrm{Sr}_{9} \mathrm{Gd}\left(\mathrm{VO}_{4}\right)_{7}, \mathrm{CaAl}_{2} \mathrm{Si}_{2} \mathrm{O}_{8}$ phosphors, ${ }^{20}$ as well as $\mathrm{Bi}^{2+}$ in $\beta-\mathrm{Ca}_{2} \mathrm{P}_{2} \mathrm{O}_{7}$ crystals, ${ }^{21}$ have been solved though the bond energy method. Furthermore, this method was also used in study of bond energy and preferential occupancy of $\mathrm{Eu}^{3+}$ doped in the $\mathrm{Ca}_{10} \mathrm{M}\left(\mathrm{PO}_{4}\right)_{7}(\mathrm{M}=\mathrm{Li}, \mathrm{Na}, \mathrm{K})$ systems. ${ }^{22}$

In our work, $\mathrm{Eu}^{3+}$ doped $\mathrm{Ca}_{5}\left(\mathrm{BO}_{3}\right)_{3} \mathrm{~F}$ was prepared by a hightemperature solid-state method. We firstly used the chemical bond parameters and analyzed the sites of Eu ion systematically based on the refined crystal structure parameters. Then, the site occupancy of $\mathrm{Eu}^{3+}$ was investigated by analyzing the luminescent properties and environmental factor $h_{\mathrm{e}}$ and the standard deviation of environmental factor (EFSD) $\sigma\left(h_{\mathrm{e}_{i}}\right)$ of $\mathrm{Ca}_{5}\left(\mathrm{BO}_{3}\right)_{3} \mathrm{~F}: 1 \% \mathrm{Eu}^{3+}$ when $\mathrm{Eu}^{3+}$ replaced the different $\mathrm{Ca}^{2+}$ sites in the matrix. Finally, the bond energy method was applied to illustrate and explain the site occupation of $\mathrm{Eu}^{3+}$ into the host lattice.

\section{Experimental}

\subsection{Synthesis of material}

$\mathrm{Ca}_{5}\left(\mathrm{BO}_{3}\right)_{3} \mathrm{~F}: 1 \% \mathrm{Eu}^{3+}$ phosphor was prepared by hightemperature solid-state reaction in air. The desired $\mathrm{CaF}_{2}$ (A.R., Macklin), $\mathrm{H}_{3} \mathrm{BO}_{3}$ (A.R., Sinopharm), $\mathrm{CaCO}_{3}$ (99.99\%, Aladdin), and $\mathrm{Eu}_{2} \mathrm{O}_{3}$ (99.99\%, Aladdin) were weighed according to the stoichiometric ratio of $\mathrm{Ca}_{5}\left(\mathrm{BO}_{3}\right)_{3} \mathrm{~F}: 1 \% \mathrm{Eu}^{3+}$, and the raw materials were placed in an agate mortar and ground for half an hour. The uniformly mixed raw materials were transferred to an alumina crucible, heated in a crucible calciner to $1150{ }^{\circ} \mathrm{C}$, and then kept for $4 \mathrm{~h}$. After the sample was cooled to room temperature, it was ground into a powder to obtain the desired sample.

\subsection{Material characterization}

In this experiment, we used a Bruker D8 Advance X-ray diffractometer to analyze the crystal structure of the prepared phosphor with $\mathrm{Cu} \mathrm{K} \alpha(\lambda=1.54056 \AA)$ radiation and acceleration voltage of $30 \mathrm{kV}$. The scanning range was 5 to 80 degrees. The sample was detected by FLS980 fluorescence spectrometer to obtain the excitation spectrum and emission spectrum. The excitation source was a $450 \mathrm{~W}$ Xe lamp with a slit width of $2 \mathrm{~nm}$ and a measured spectral range of $200 \mathrm{~nm}$ to $750 \mathrm{~nm}$, with a resolution of $0.2 \mathrm{~nm}$. The sample was tested at room temperature. The Rietveld structure refinement was performed using the General Structure Analysis System (GSAS) ${ }^{23}$ software in order to determine the change of crystal structure.

\section{Results and discussion}

\subsection{Phase characterization and crystal analysis}

Fig. 1 is an XRD pattern of $\mathrm{Ca}_{5}\left(\mathrm{BO}_{3}\right)_{3} \mathrm{~F}: 1 \% \mathrm{Eu}^{3+}$ sample. Comparing the sample diffraction pattern with the standard card, it was found that the diffraction peak data were basically consistent with the $\mathrm{Ca}_{5}\left(\mathrm{BO}_{3}\right)_{3} \mathrm{~F}$ (ICSD-65763) card data, with a $C 1 m 1$ space group and a monoclinic crystal system. There is an impurity phase, namely, $\mathrm{Ca}_{3} \mathrm{~B}_{2} \mathrm{O}_{6}$. Fortunately, a very small amount of $\mathrm{Ca}_{3} \mathrm{~B}_{2} \mathrm{O}_{6}$ has no effect on our system. Therefore, the substitution of $\mathrm{Eu}^{3+}$ for $\mathrm{Ca}^{2+}$ into $\mathrm{Ca}_{5}\left(\mathrm{BO}_{3}\right)_{3} \mathrm{~F}$ did not change the structure of the crystal.

Fig. 2 shows the crystal structure of $\mathrm{Ca}_{5}\left(\mathrm{BO}_{3}\right)_{3} \mathrm{~F}$. There are three $\mathrm{Ca}$ ion coordination environments in this structure, namely, $\mathrm{Ca} 1, \mathrm{Ca} 2$ and $\mathrm{Ca} 3$. The anionic structural group of the $\mathrm{Ca}_{5}\left(\mathrm{BO}_{3}\right)_{3} \mathrm{~F}$ crystal is a planar $\mathrm{BO}_{3}$ group. Both $\mathrm{Ca}$ and the surrounding anions form a $\mathrm{CaO}_{4} \mathrm{X}_{2}(\mathrm{X}=\mathrm{F}$ or $\mathrm{O})$ octacoordination, in which $\mathrm{Ca}(1)$ forms a $\mathrm{CaO}_{5} \mathrm{~F}$ octahedron with five $\mathrm{O}$ atoms and one $\mathrm{F}$ atom, and $\mathrm{Ca}(2)$ forms a distorted octahedral structure with six $\mathrm{O}$ atoms. $\mathrm{Ca}(3)$ is coordinated with two $\mathrm{F}$ atoms and four $\mathrm{O}$ atoms. These polyhedrons are connected to the $\mathrm{BO}_{3}$ group by sharing $\mathrm{O}$ atoms to form a threedimensional space structure.

The crystal structure of $\mathrm{Ca}_{5}\left(\mathrm{BO}_{3}\right)_{3} \mathrm{~F}$ (ICSD-65763) was used as the starting model for structure refinement. The Rietveld method refers to the point-by-point comparison of the calculated and measured values of the diffraction intensity of a crystal using a computer program, and the least squares method is used to adjust the parameters of the structural atoms and of the peak shape, so that the calculated peak shape is consistent with the measured peak shape. In the structural

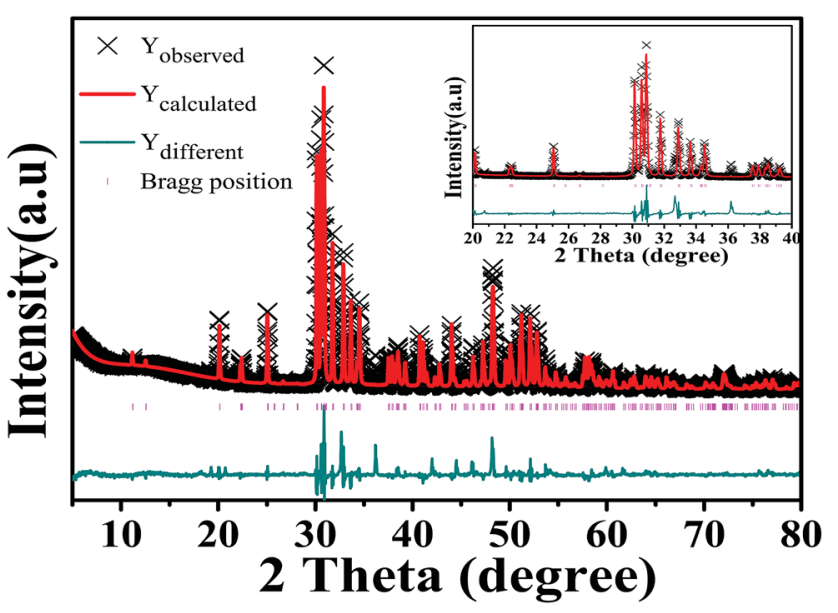

Fig. 1 Observed, calculated and difference $X$-ray diffraction patterns of an $\mathrm{Eu}^{3+}(1 \%)$-doped $\mathrm{Ca}_{5}\left(\mathrm{BO}_{3}\right)_{3} \mathrm{~F}$ phosphor (the inset gives [20-40] $2 \theta$ range). 


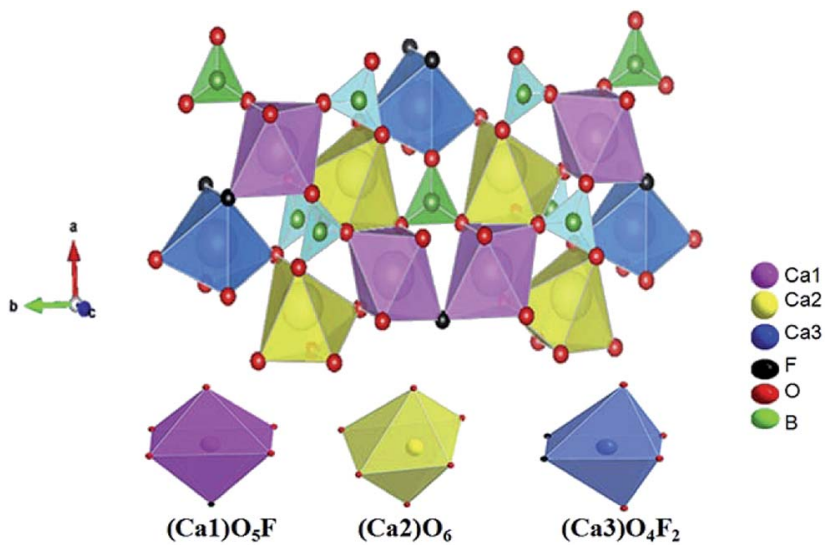

Fig. 2 Crystal structure of $\mathrm{Ca}_{5}\left(\mathrm{BO}_{3}\right)_{3} \mathrm{~F}$ and the coordination environment of $\mathrm{Ca} 1, \mathrm{Ca} 2$, and $\mathrm{Ca} 3$.

Table 1 Final crystallographic and refinement of parameter of $\mathrm{Ca}_{5}\left(\mathrm{BO}_{3}\right)_{3} \mathrm{~F}: 1 \% \mathrm{Eu}^{3+} ; \mathrm{E}$ is the error between the original and refined value

\begin{tabular}{lll}
\hline Formula & $\mathrm{Ca}_{5}\left(\mathrm{BO}_{3}\right)_{3} \mathrm{~F}$ & $E$ \\
Space-group & $C 1 m 1$ & \\
$a / \AA$ & 8.132 & 0.003 \\
$b / \AA$ & 16.054 & 0.003 \\
$c / \AA$ & 3.542 & 0.003 \\
$\alpha=\gamma$ & $90^{\circ}$ & 0 \\
$\beta$ & $100.946^{\circ}$ & 0 \\
$R_{\mathrm{wp}}$ & $5.30 \%$ & \\
$R_{\mathrm{p}}$ & $9.35 \%$ & \\
$\chi^{2}$ & 6.806 &
\end{tabular}

refinement of this paper, based on the XRD peak of the existing $\mathrm{Ca}_{5}\left(\mathrm{BO}_{3}\right)_{3} \mathrm{~F}: 1 \% \mathrm{Eu}^{3+}$ crystal and $\mathrm{Ca}_{5}\left(\mathrm{BO}_{3}\right)_{3} \mathrm{~F}$ standard card as the background, the set function is type 4 , and about 30 terms were refined. Fig. 1 shows the observed, calculated and difference results for the Rietveld refinement of $\mathrm{Ca}_{5}\left(\mathrm{BO}_{3}\right)_{3} \mathrm{~F}: 1 \% \mathrm{Eu}^{3+}$ phosphor. The peak intensities and positions exhibited few differences between the experimental and calculated patterns. Crystallographic and refinement parameters are summarized in Table 1. The results show that almost all diffraction peaks can be directed to $\mathrm{Ca}_{5}\left(\mathrm{BO}_{3}\right)_{3} \mathrm{~F}$ with a monoclinic unit cell $(\mathrm{C} 1 \mathrm{~m} 1)$.
The cell parameters $a, b, c$, and $\beta$, etc., are close to those of $\mathrm{Ca}_{5}\left(\mathrm{BO}_{3}\right)_{3} \mathrm{~F}$ (ICSD-65763). The atomic coordinates and isotropic displacement parameters of $\mathrm{Ca}_{5}\left(\mathrm{BO}_{3}\right)_{3} \mathrm{~F}: 1 \% \mathrm{Eu}^{3+}$ phosphor are listed in Table 2. The above results show that the crystal structure data of $\mathrm{Ca}_{5}\left(\mathrm{BO}_{3}\right)_{3} \mathrm{~F}: 1 \% \mathrm{Eu}^{3+}$ simulated by refinement can be well matched with its experimental data.

\subsection{Photoluminescence properties}

Fig. 3(b) is an excitation spectrum of the $\mathrm{Ca}_{5}\left(\mathrm{BO}_{3}\right)_{3} \mathrm{~F}: 1 \% \mathrm{Eu}^{3+}$ sample at a monitoring wavelength of $633 \mathrm{~nm}$, which is composed of a broad excitation band of $225-350 \mathrm{~nm}$, derived from the charge transfer transition of $\mathrm{O}^{2-}$ to $\mathrm{Eu}^{3+}$, where the strongest absorption peak is at $266 \mathrm{~nm}$. The emission spectrum at an excitation wavelength of $266 \mathrm{~nm}$ is shown in Fig. 3(d), consisting of emission peaks at around 576, 592, 612, 652 and $708 \mathrm{~nm}$, corresponding to ${ }^{5} \mathrm{D}_{0} \rightarrow{ }^{7} \mathrm{~F}_{0},{ }^{5} \mathrm{D}_{0} \rightarrow{ }^{7} \mathrm{~F}_{1},{ }^{5} \mathrm{D}_{0} \rightarrow{ }^{7} \mathrm{~F}_{2},{ }^{5} \mathrm{D}_{0}$ $\rightarrow{ }^{7} \mathrm{~F}_{3}$, and ${ }^{5} \mathrm{D}_{0} \rightarrow{ }^{7} \mathrm{~F}_{4}$ transitions of $\mathrm{Eu}^{3+}$ ions, respectively. ${ }^{24,25}$ We can clearly see that the charge transfer transition peaks of samples $\mathrm{O}$ to $\mathrm{Eu}$ have a significant shift when the monitoring wavelengths are 576, 612, 619 and $633 \mathrm{~nm}$, as shown in Fig. 3(a) and (b). The two broadband peaks $\left(\mathrm{O}^{2-} \rightarrow \mathrm{Eu}^{3+}\right)$ are located at 266 and $283 \mathrm{~nm}$, respectively, which means that the $\mathrm{Eu}^{3+}$ ions exhibit two lattice environments in the $\mathrm{Ca}_{5}\left(\mathrm{BO}_{3}\right)_{3} \mathrm{~F}$ matrix. However, the excitation and emission spectra of Eu-doped $\mathrm{Ca}_{3} \mathrm{~B}_{2} \mathrm{O}_{6}$ are completely different with our luminescence properties of Eu-doped $\mathrm{Ca}_{5}\left(\mathrm{BO}_{3}\right)_{3} \mathrm{~F}$. The former shows an emission band peaking at $422 \mathrm{~nm}$ and excitation peaks at 362, 380 and $394 \mathrm{~nm}\left(\lambda_{\mathrm{em}}=616 \mathrm{~nm}\right)$. These prove that the different luminescence of Eu is due to Eu occupying the different sites in the $\mathrm{Ca}_{5}\left(\mathrm{BO}_{3}\right)_{3} \mathrm{~F}^{26}$

When the $\mathrm{Eu}^{3+}$ ion deviates from the center of the inversion, due to the opposite parity configuration in the $4 \mathrm{f}$ configuration, the parity selection in the crystal is relaxed and the ${ }^{5} \mathrm{D}_{0} \rightarrow{ }^{7} \mathrm{~F}_{2}$ electric dipole transition will occur. If the $\mathrm{Eu}^{3+}$ ion is located in the non-inversion center, its emission spectrum will be dominated by the ${ }^{5} \mathrm{D}_{0} \rightarrow{ }^{7} \mathrm{~F}_{2}$ electric dipole transition, and the emission spectrum will be around $610 \mathrm{~nm}$. For the electronic transition of $\mathrm{Eu}^{3+}$ ion, the ${ }^{5} \mathrm{D}_{0} \rightarrow{ }^{7} \mathrm{~F}_{0}$ transition originally belongs to the forbidden transition. However, when it is in the ten symmetry positions of $C_{\mathrm{s}}, C_{1}, C_{2}, C_{3}, C_{4}, C_{6}, C_{2 \mathrm{~V}}, C_{3 \mathrm{~V}}, C_{4 \mathrm{~V}}$ and $C_{6 \mathrm{~V}},{ }^{5} \mathrm{D}_{0} \rightarrow{ }^{7} \mathrm{~F}_{0}$ transition emission will occur, and the emission

Table 2 Atomic coordinates and isotropic displacement parameters $\left(U_{\text {iso }} / \AA^{2}\right)$ for $\mathrm{Ca}_{5}\left(\mathrm{BO}_{3}\right)_{3} \mathrm{~F}: 1 \% \mathrm{Eu}{ }^{3+}$; $E$ is the error between the original and refined value

\begin{tabular}{|c|c|c|c|c|c|c|c|c|}
\hline Name & $x$ & $y$ & $z$ & $E_{\text {position }}$ & Mult & Occ & $U_{\text {iso }}$ & $E_{U_{\text {iso }}}$ \\
\hline Ca1 & 0.6501 & 0.1177 & 0.7786 & 0.013 & 4 & 1 & 0.0231 & 0.001 \\
\hline $\mathrm{Ca} 2$ & 0.0278 & 0.1796 & 0.4421 & 0.02 & 4 & 1 & 0.0145 & 0.002 \\
\hline F1 & 0.4691 & 0 & -0.3287 & 0.03 & 2 & 1 & 0.0737 & 0.01 \\
\hline O1 & 0.8282 & 0.0743 & 0.3639 & 0.01 & 4 & 1 & 0.0603 & 0.002 \\
\hline $\mathrm{O} 2$ & -0.001 & 0.3279 & 0.2448 & 0.018 & 4 & 1 & 0.0504 & 0.001 \\
\hline O5 & 0.2071 & 0.143 & 0.0125 & 0.02 & 4 & 1 & 0.0134 & 0.001 \\
\hline B1 & 0.8626 & 0.307 & 0.0036 & 0.014 & 4 & 1 & 0.0594 & 0.011 \\
\hline B2 & 0.9239 & 0 & 0.3499 & 0.006 & 2 & 1 & -0.0113 & 0.003 \\
\hline
\end{tabular}



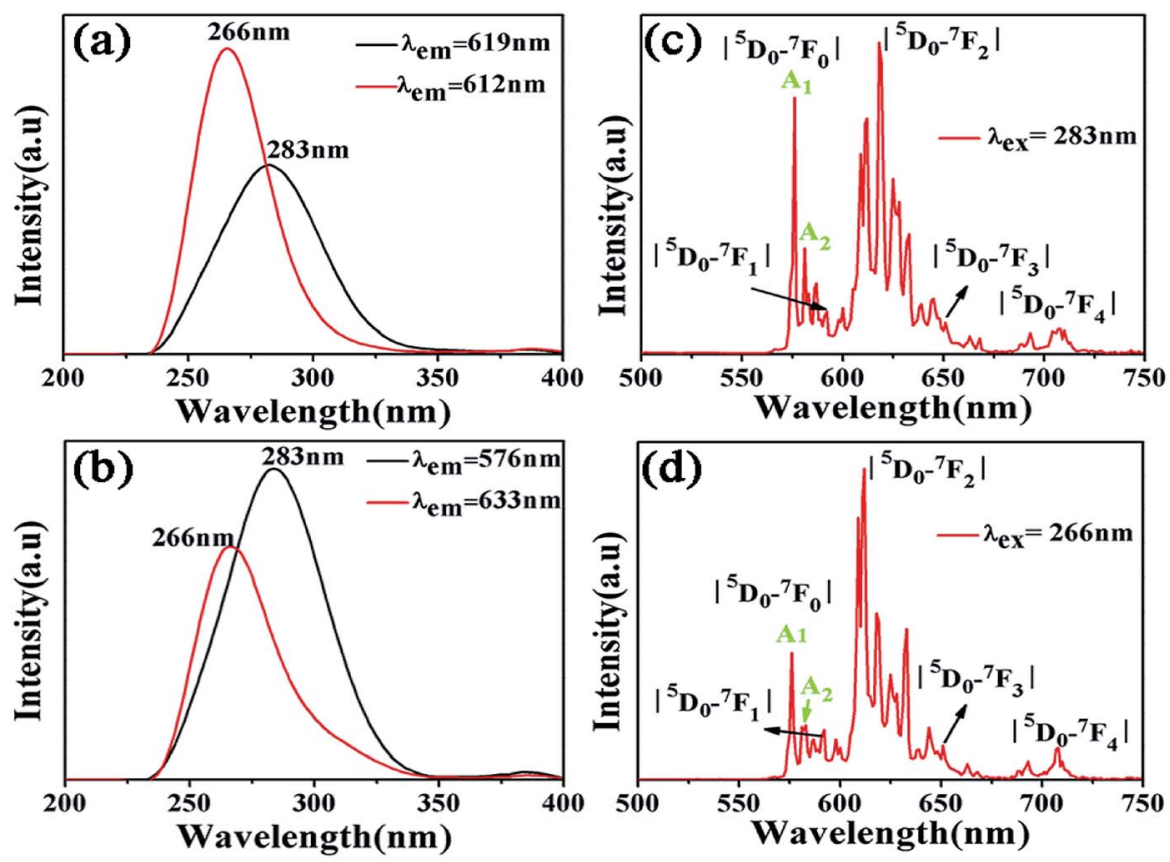

Fig. 3 (a) and (b) Excitation spectra under different monitoring wavelengths of $\mathrm{Ca}_{5}\left(\mathrm{BO}_{3}\right)_{3} \mathrm{~F}: 1 \% \mathrm{Eu}^{3+}$; (c) and (d) emission spectra of $\mathrm{Ca}_{5}(\mathrm{BO})_{3} \mathrm{~F}: 1 \%$ $\mathrm{Eu}^{3+}$ under 266 and $283 \mathrm{~nm}$ excitation.

spectrum peak will be around $580 \mathrm{~nm} . \mathrm{A}^{5} \mathrm{D}_{0} \rightarrow{ }^{7} \mathrm{~F}_{0}$ transition peak appears in each site. ${ }^{27}$ Therefore, based on the number of the peaks, the number of occupied sites of the $\mathrm{Eu}^{3+}$ ion crystals can be judged. Fig. 3(c) and (d) show the emission spectra of $\mathrm{Ca}_{5}\left(\mathrm{BO}_{3}\right)_{3} \mathrm{~F}: 1 \% \mathrm{Eu}^{3+}$ upon excitation at $266 \mathrm{~nm}$ and $283 \mathrm{~nm}$, respectively. Their peaks locate at $576 \mathrm{~nm}$, which is due to ${ }^{5} \mathrm{D}_{0}$ $\rightarrow{ }^{7} \mathrm{~F}_{0}$ transition of $\mathrm{Eu}^{3+}$ ions. Each ${ }^{5} \mathrm{D}_{0} \rightarrow{ }^{7} \mathrm{~F}_{0}$ transition peak corresponds to a lattice. Two ${ }^{5} \mathrm{D}_{0} \rightarrow{ }^{7} \mathrm{~F}_{0}$ peaks, $\mathrm{A}_{1}$ and $\mathrm{A}_{2}$, were found in Fig. 3(c) and (d), which indicate that $\mathrm{Eu}^{3+}$ doping in $\mathrm{Ca}_{5}\left(\mathrm{BO}_{3}\right)_{3} \mathrm{~F}$ has two sites. ${ }^{28-30}$ The data are shown in Table 3 for the luminescent levels of $\mathrm{Ca}_{5}\left(\mathrm{BO}_{3}\right)_{3} \mathrm{~F}: 1 \% \mathrm{Eu}^{3+}$ upon 266 and $283 \mathrm{~nm}$ excitation.

Since CT energy is susceptible to the central ionic environment, it can be quantitatively expressed by using environmental factors $\left(h_{\mathrm{e}}\right) . h_{\mathrm{e}}$ consists of four chemical bond parameters: the bond volume polarization $\left(\alpha_{\mathrm{b}}{ }^{\mu}\right)$, the covalency $\left(f_{\mathrm{c}}{ }^{\mu}\right)$, the coordination number (C. N.) and the presented charge of the ligand $\left(Q_{\mathrm{B}}{ }^{\mu}\right)$. Its calculation formula is as follows: ${ }^{31}$

$$
h_{\mathrm{e}}=\left(\sum_{\mu} f_{\mathrm{c}}{ }^{\mu} \alpha_{\mathrm{b}}{ }^{\mu} Q_{\mathrm{B}}{ }^{\mu 2}\right)^{1 / 2}
$$

where $f_{\mathrm{c}}{ }^{\mu}$ represents the covalent value of $\mu$ type bond, $Q_{\mathrm{B}}{ }^{\mu}$ is the charge exhibited by the nearest anion and $\alpha_{\mathrm{b}}{ }^{\mu}$ stands for the polarizability of the $\mu$-type chemical bond volume.

The four chemical bond parameters, with any change, will cause a shift in the CT bands. As $h_{\mathrm{e}}$ increases, the CT energy decreases, which means that the CT bands will produce a red shift. In Table 4 , we can see that the $h_{\mathrm{e}}$ values of Ca1, Ca2, and Ca3 are $0.6397,0.7439$, and 0.3514 , respectively. Therefore, it can be known that Eu will occupy the Ca1 and Ca2 sites, and at the same time, the O-Eu1 CT band at the Ca1 site corresponds to the peak at $266 \mathrm{~nm}$ and the O-Eu2 CT band at Ca2 corresponds to the position at $283 \mathrm{~nm}$.

Obviously, the intensity of $\mathrm{f}-\mathrm{f}$ transitions is affected by the crystal environment because of the different symmetry of the doping ions occupying the host sites. When the $\mathrm{Eu}^{3+}$ is doped into $\mathrm{Ca}_{5}\left(\mathrm{BO}_{3}\right)_{3} \mathrm{~F}$, the Eu ions occupy the $\mathrm{Ca}^{2+}$ sites, wherefore,

Table 3 The data for the luminescent levels of $\mathrm{Ca}_{5}\left(\mathrm{BO}_{3}\right)_{3} \mathrm{~F}: 1 \% \mathrm{Eu}^{3+}$ upon 266 and $283 \mathrm{~nm}$ excitation

\begin{tabular}{|c|c|c|c|c|}
\hline Energy level transition & $\begin{array}{l}\text { The location of the } \\
\text { peak }(\mathrm{nm})\left(\lambda_{\mathrm{ex}}=266 \mathrm{~nm}\right)\end{array}$ & Intensity & $\begin{array}{l}\text { The location of the } \\
\text { peak }(\mathrm{nm})\left(\lambda_{\mathrm{ex}}=283 \mathrm{~nm}\right)\end{array}$ & Intensity \\
\hline${ }^{5} \mathrm{D}_{0} \rightarrow{ }^{7} \mathrm{~F}_{0}$ & 576 & & 576 & \\
\hline${ }^{5} \mathrm{D}_{0} \rightarrow{ }^{7} \mathrm{~F}_{1}$ & 592 & 233668.172 & 592 & 149367.984 \\
\hline${ }^{5} \mathrm{D}_{0} \rightarrow{ }^{7} \mathrm{~F}_{2}$ & 612 & 685254.813 & 618 & 1102500 \\
\hline${ }^{5} \mathrm{D}_{0} \rightarrow{ }^{7} \mathrm{~F}_{3}$ & 652 & & 651 & \\
\hline
\end{tabular}


Table 4 The chemical bond parameters, environmental factor $h_{\mathrm{e}}$, the experimental $\mathrm{O}^{2} \rightarrow \mathrm{Eu}^{3+}$ charge transfer band, the environmental factor of any individual bond $\left(h_{\mathrm{e}_{i}}\right)$ and their standard deviation of the $\mathrm{Ca}-\mathrm{O}$ environmental factors $\sigma\left(h_{\mathrm{e}_{i}}\right)$

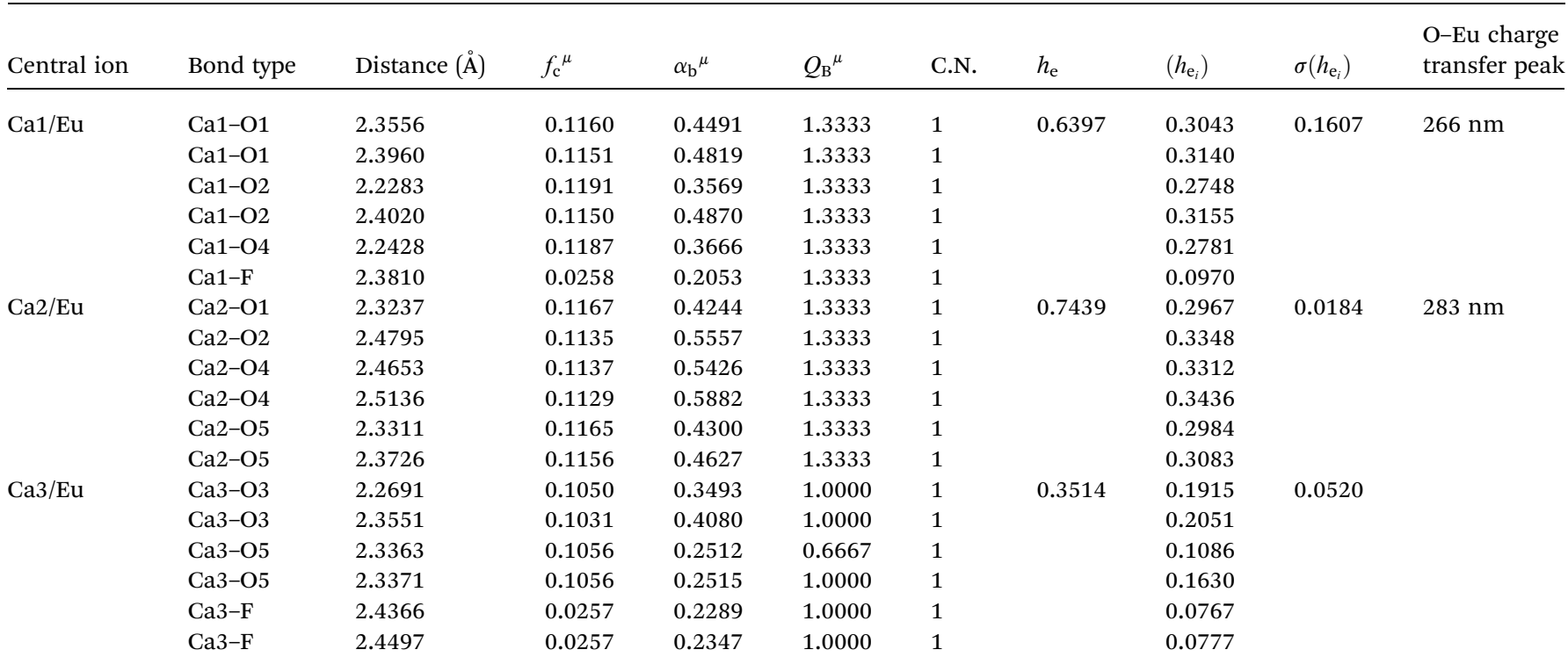

the $\mathrm{f}-\mathrm{f}$ transition relative intensity is mainly affected by the $\mathrm{Ca}^{2+}$ symmetry. The different ${ }^{5} \mathrm{D}_{0} \rightarrow{ }^{7} \mathrm{~F}_{\mathrm{J}}$ transition intensities of $\mathrm{Eu}^{3+}$ depend on the local symmetry of the $\mathrm{Eu}^{3+}$ ion crystal field. The ${ }^{5} \mathrm{D}_{0} \rightarrow{ }^{7} \mathrm{~F}_{2}$ transition is sensitive, while the ${ }^{5} \mathrm{D}_{0} \rightarrow{ }^{7} \mathrm{~F}_{1}$ transition is stable to the crystal field environment. For example, when the $\mathrm{Eu}^{3+}$ ion is in a site with a strict inversion center, it will be dominated by the allowable ${ }^{5} \mathrm{D}_{0} \rightarrow{ }^{7} \mathrm{~F}_{1}$ magnetic dipole transition, and the emission spectrum is around $590 \mathrm{~nm}$, which is orange light. When the $\mathrm{Eu}^{3+}$ ion is in the site away from the inversion center, the parity selection in the crystal is relaxed, and a ${ }^{5} \mathrm{D}_{0} \rightarrow{ }^{7} \mathrm{~F}_{2}$ electric dipole transition will occur; the emission spectrum is around $610 \mathrm{~nm}$, emitting red light. If the intensity of the ${ }^{5} \mathrm{D}_{0} \rightarrow{ }^{7} \mathrm{~F}_{2}$ transition is much higher than the intensity of ${ }^{5} \mathrm{D}_{0} \rightarrow{ }^{7} \mathrm{~F}_{1}$, the $\mathrm{Eu}^{3+}$ ion mainly occupies the noninversion symmetry of the lattice. It is known that the PL intensity ratio between ${ }^{5} \mathrm{D}_{0} \rightarrow{ }^{7} \mathrm{~F}_{2}$ and ${ }^{5} \mathrm{D}_{0} \rightarrow{ }^{7} \mathrm{~F}_{1}$ transition of $\mathrm{Eu}^{3+}$ increases as the crystal distortion increases. The degree of distortion can be calculated by using the standard deviation of

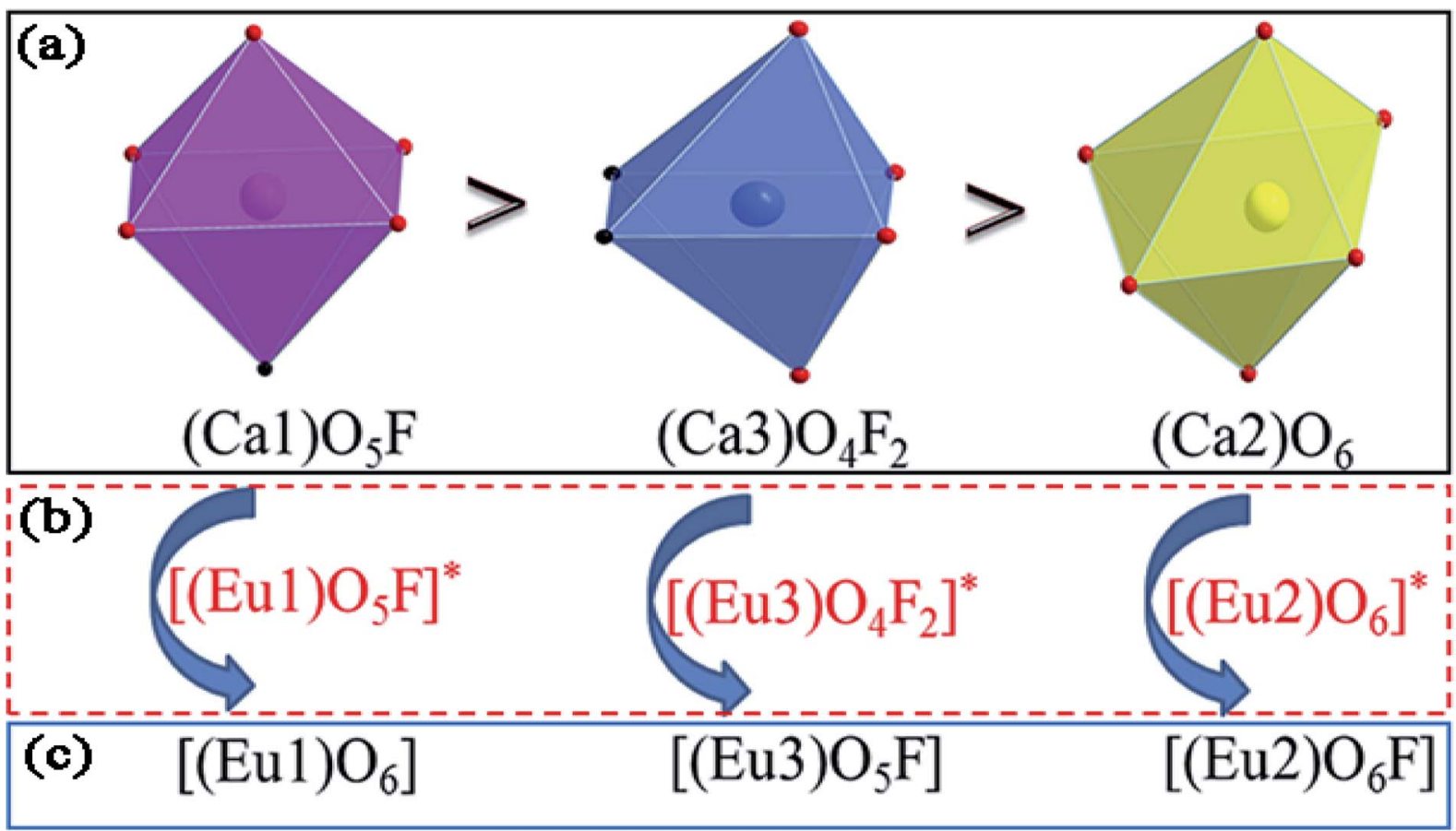

Fig. 4 The coordination environment mechanism of $\mathrm{Ca} 1$ (or Eu1), Ca2 (or Eu2), and $\mathrm{Ca} 3$ (or Eu3) in $\mathrm{Ca}_{5}\left(\mathrm{BO}_{3}\right)_{3} \mathrm{~F}: 1 \% \mathrm{Eu}$ 
Table 5 Required $d_{0}$ and $J$ values

\begin{tabular}{lll}
\hline Ions & $d_{0}(\AA)$ & $J\left(\mathrm{kcal} \mathrm{mol}^{-1}\right)$ \\
\hline $\mathrm{Ca}^{2+}-\mathrm{O}^{2-}$ & 1.967 & 126.60 \\
$\mathrm{Ca}^{2+}-\mathrm{F}^{-}$ & 1.842 & 187.03 \\
$\mathrm{~B}^{3+}-\mathrm{O}^{2-}$ & 1.371 & 126.30 \\
$\mathrm{Eu}^{3+}-\mathrm{F}^{-}$ & 2.056 & 163.35 \\
$\mathrm{Eu}^{3+}-\mathrm{O}^{2-}$ & 2.074 & 109.40
\end{tabular}

environmental factor (EFSD) $\sigma\left(h_{\mathrm{e}_{i}}\right),{ }^{22,32}$ which can be calculated as below:

$$
\sigma\left(h_{\mathrm{e}_{i}}\right)=\sqrt{\frac{1}{N} \sum_{i=1}^{N}\left(h_{\mathrm{e}_{i}}-\delta\right)^{2}}
$$

where

$$
h_{\mathrm{e}_{i}}=\left(f_{\mathrm{c}}{ }^{\mu} \alpha_{\mathrm{b}}{ }^{\mu}\right)^{1 / 2} Q_{\mathrm{B}}{ }^{\mu}
$$

and

$$
\delta=\frac{1}{N} \sum_{i=1}^{N} h_{\mathrm{e}_{i}}
$$

The related chemical parameters of the covalency $f_{\mathrm{c}}{ }^{\mu}$, the present charge of the ligand in the binary crystals, and the polarizability of the chemical bond volume $\alpha_{\mathrm{b}}{ }^{\mu}$ are shown in Table 4 . On the basis of the eqn (2)-(4), their standard deviation for the six Ca-O environmental factors $\left(\sigma\left(h_{\mathrm{e}_{i}}\right)\right)$ of $\mathrm{Ca}_{10} \mathrm{O}_{5} \mathrm{~F}$,
$\mathrm{Ca} 2 \mathrm{O}_{4} \mathrm{~F}_{2}$, and $\mathrm{Ca} 3 \mathrm{O}_{6}$ polyhedrons in $\mathrm{Ca}_{5}\left(\mathrm{BO}_{3}\right)_{3} \mathrm{~F}: 1 \%$ Eu can be calculated to be $0.1607,0.0184$ and 0.052 , respectively. Generally, the $I\left({ }^{5} \mathrm{D}_{0} /{ }^{7} \mathrm{~F}_{2}\right) / I\left({ }^{5} \mathrm{D}_{0} /{ }^{7} \mathrm{~F}_{1}\right)$ value of $\mathrm{Eu}^{3+}$ increases with increasing $\sigma\left(h_{\mathrm{e}_{i}}\right)$. The $\sigma\left(h_{\mathrm{e}_{i}}\right)$ value of $\mathrm{Ca}_{1} \mathrm{O}_{5} \mathrm{~F}$ in $\mathrm{Ca}_{5}\left(\mathrm{BO}_{3}\right)_{3} \mathrm{~F}: 1 \%$ $\mathrm{Eu}$ is larger than that of $\mathrm{Ca}_{2} \mathrm{O}_{4} \mathrm{~F}_{2}$. By comparison, the intensity ratio of ${ }^{5} \mathrm{D}_{0} \rightarrow{ }^{7} \mathrm{~F}_{2}$ transition to the ${ }^{5} \mathrm{D}_{0} \rightarrow{ }^{7} \mathrm{~F}_{1}$ transition of $\mathrm{Eu}^{3+}$ at $\mathrm{Ca} 2$ (7.381) is 2.5 times stronger than that of $\mathrm{Eu}^{3+}$ at Ca1 site (2.933). Therefore, the $I\left({ }^{5} \mathrm{D}_{0} \rightarrow{ }^{7} \mathrm{~F}_{2}\right) / I\left({ }^{5} \mathrm{D}_{0} \rightarrow{ }^{7} \mathrm{~F}_{1}\right)$ of $\mathrm{Eu}^{3+}$ in the $\mathrm{Ca}^{3} \mathrm{O}_{5} \mathrm{~F}$ site is stronger than that in the $\mathrm{Ca}_{2} \mathrm{O}_{4} \mathrm{~F}_{2}$ site. Ca1 and $\mathrm{Ca} 2$ correspond to excitations at $283 \mathrm{~nm}$ and $266 \mathrm{~nm}$, respectively. However, this is contrary to the conclusion drawn in Table 4. In ideal state, the order of $\sigma\left(h_{\mathrm{e}_{i}}\right)$ is in Fig. 4. When $\mathrm{Eu}^{3+}$ is doped into $\mathrm{Ca}_{5}\left(\mathrm{BO}_{3}\right)_{3} \mathrm{~F}$, part of the $\mathrm{Ca}^{2+}$ ions must be occupied by $\mathrm{Eu}^{3+}$, so the local environment of $\mathrm{Eu}^{3+}$ must be changed in order to keep the conservation of charge in Fig. 4(a) and (b). At this time, one $\mathrm{F}$ of the substationary $\left[(\mathrm{Eu} 1) \mathrm{O}_{5} \mathrm{~F}\right]^{*}$ and $\left[(\mathrm{Eu} 3) \mathrm{O}_{4} \mathrm{~F}_{2}\right]^{*}$ will be replaced by an $\mathrm{O}$ to maintain their own stability; $\left[(\mathrm{Eu} 2) \mathrm{O}_{6}\right]^{*}$ will receive an $\mathrm{F}$, and it will eventually become a 7-coordinated environment in Fig. 4(c). In summary, we can conclude that the Ca2 distortion degree should be greater than that of Ca1. Therefore, $\mathrm{Ca} 1$ and $\mathrm{Ca} 2$ correspond to excitations at $266 \mathrm{~nm}$ and $283 \mathrm{~nm}$, respectively, consistent with the results obtained in Table 4 .

\subsection{Chemical bond energy calculation}

From the point of view of matched valence, the bond energy of $\mathrm{Eu}^{3+}$ into the $\mathrm{Ca}_{5}\left(\mathrm{BO}_{3}\right)_{3} \mathrm{~F}$ phosphor can be estimated by the following equation, ${ }^{20,33}$

Table 6 The bond parameters of the central atom and values of bond energy when $\mathrm{Eu}^{3+}$ locates at $\mathrm{Ca}$ and $\mathrm{B}$ sites in $\mathrm{Ca}{ }_{5}(\mathrm{BO})_{3} \mathrm{~F} \mathrm{All}$ of the bond energy units are $\mathrm{kcal} \mathrm{mol}^{-1}$

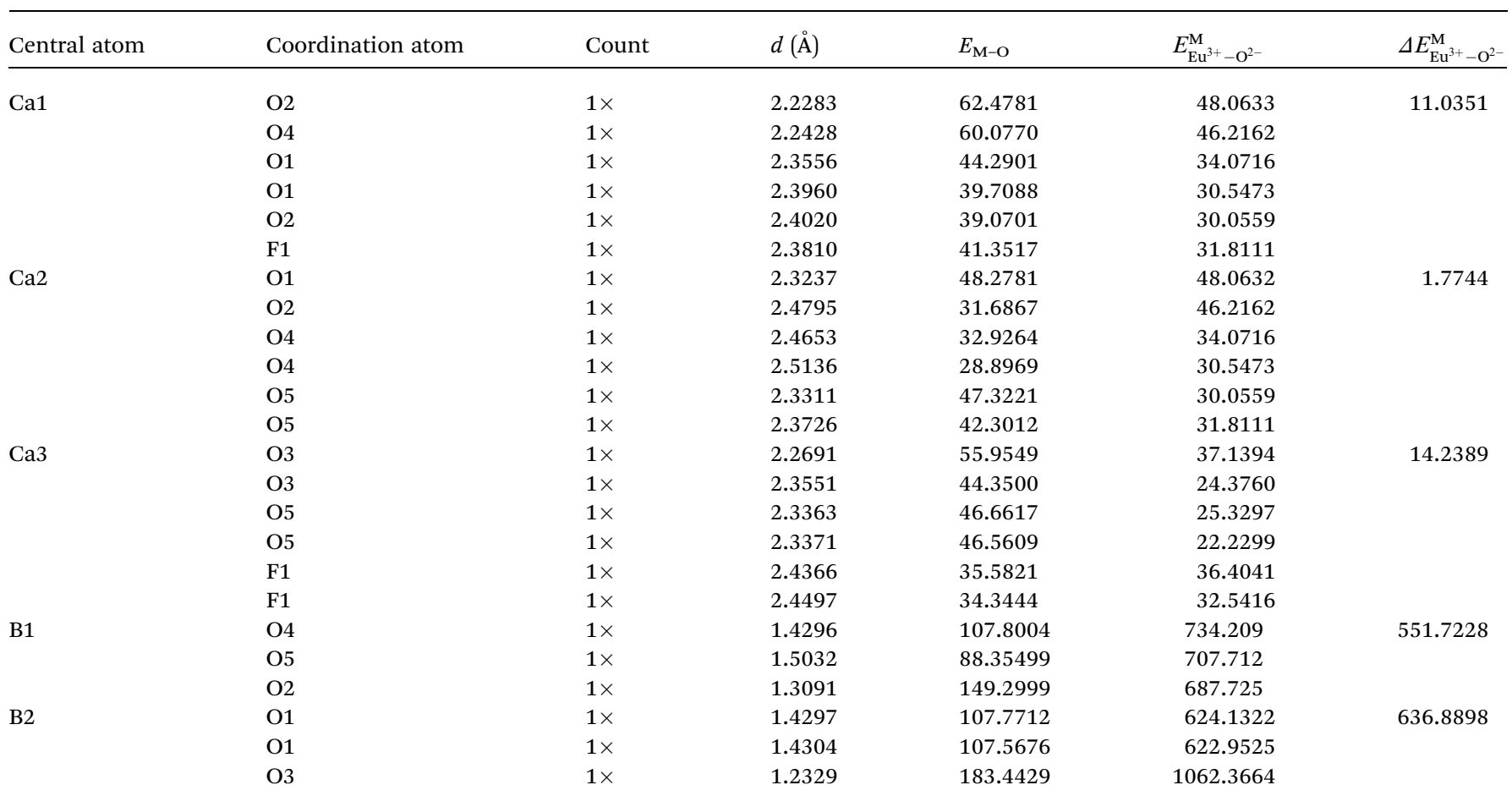




$$
E_{\mathrm{M}-\mathrm{O}}=J \exp \left(\frac{d_{0}-d_{\mathrm{M}-\mathrm{O}}}{0.37}\right)\left(\frac{V_{\mathrm{N}}}{V_{\mathrm{M}}}\right)
$$

where $V_{\mathrm{M}}$ presents the dopant valence and $V_{\mathrm{N}}$ stands for the valence state of $\mathrm{N}$. When the pure $\mathrm{Ca}_{5}\left(\mathrm{BO}_{3}\right)_{3} \mathrm{~F}$ phosphor does not have any dopant, the value of $V_{\mathrm{N}} / V_{\mathrm{M}}$ is 1 . This indicates that the valence state has no effect on the bond energy. If $V_{\mathrm{N}} / V_{\mathrm{M}}$ is not equal to 1 , it implies that the valence state effectively affects the crystal bond energy. Consequently, the effect of different valence states of the dopant on the $\mathrm{Ca}^{2+}$ site bond energy can be quantitatively described through eqn (5). The $J$ and $d_{0}$ values are given in the report of $\mathrm{Li}^{34} d_{\mathrm{M}-\mathrm{O}}$ represents the bond length between atoms $\mathrm{M}$ and $\mathrm{O}$. Required $d_{0}$ and $J$ value tables are in Table 5. When Eu enters $\mathrm{Ca}_{5}\left(\mathrm{BO}_{3}\right)_{3} \mathrm{~F}$, the bond energy difference is calculated by the following equation:

$$
\Delta E_{\mathrm{M}-\mathrm{O}}^{\mathrm{Eu}}=\left|E_{\mathrm{M}-\mathrm{O}}-E_{\mathrm{Eu}-\mathrm{O}}\right|
$$

Here, $\Delta E_{\mathrm{M}-\mathrm{O}}^{\mathrm{Eu}}$ is the bond energy difference when the Eu ion locates at the site of $\mathrm{Ca}^{2+}$. As previously reported, we can know that the dopants preferentially occupy a site where the bond energy difference is small $\left(\Delta E_{\mathrm{M}-\mathrm{O}}^{\mathrm{Eu}}\right)$, that is, a site having a smaller absolute value of $\Delta E_{\mathrm{M}-\mathrm{O}}^{\mathrm{Eu}}{ }^{20}$

According to the detailed crystallographic data from a pure $\mathrm{Ca}_{5}\left(\mathrm{BO}_{3}\right)_{3} \mathrm{~F}$ phosphor (longer $\mathrm{Ca}-\mathrm{O}$ bonds of $1.967 \AA$; shorter B-O bonds of $1.371 \AA$; longer $\mathrm{Ca}-\mathrm{F}$ bonds of $1.842 \AA$ ), all calculated $E_{\mathrm{M}-\mathrm{O}}$ and $\Delta E_{\mathrm{M}-\mathrm{O}}$ values of $\mathrm{Eu}^{3+}$ on both $\mathrm{Ca}^{2+}$ and $\mathrm{B}^{3+}$ sites are shown in Table 6. The corresponding occupancies of $\mathrm{Eu}^{3+}$ are summarized, according to the calculated $\Delta E_{\mathrm{M}-\mathrm{O}}^{\mathrm{M}}$ values. Dopants preferentially occupy the sites where the bond energy difference $\left(\Delta E_{\mathrm{M}-\mathrm{O}}^{\mathrm{M}}\right)$ is smaller; that is, $\mathrm{Eu}^{3+}$ ions preferentially occupy $\mathrm{Ca}^{2+}$ sites if $\left|\Delta E_{\mathrm{Eu}-\mathrm{O}}^{\mathrm{Ca}}\right|<\left|\Delta E_{\mathrm{Eu}-\mathrm{O}}^{\mathrm{B}}\right|$; they preferentially occupy $\mathrm{B}^{3+}$ sites if $\left|\Delta E_{\mathrm{Eu}-\mathrm{O}}^{\mathrm{Ca}}\right|>\left|\Delta E_{\mathrm{Eu}-\mathrm{O}}^{\mathrm{B}}\right|$, otherwise.

There are three $\mathrm{Ca}^{2+}$ sites and two $\mathrm{B}^{3+}$ sites in the structure of $\mathrm{Ca}_{5}\left(\mathrm{BO}_{3}\right)_{3} \mathrm{~F}$. On the basis of the bond energy method, the values of $\Delta E_{\mathrm{Eu}-\mathrm{O}}^{\mathrm{Ca}}$ and $\Delta E_{\mathrm{Eu}-\mathrm{O}}^{\mathrm{B}}$ have been listed in Table 6 . The order of difference of bond energy that $\mathrm{Ca}^{2+}$ and $\mathrm{B}^{3+}$ ions are replaced by $\mathrm{Eu}^{3+}$ is $\Delta E_{\mathrm{Eu}-\mathrm{O}}^{\mathrm{Ca} 2}<\Delta E_{\mathrm{Eu}-\mathrm{O}}^{\mathrm{Ca}}<\Delta E_{\mathrm{Eu}-\mathrm{O}}^{\mathrm{Ca}} \ll \Delta E_{\mathrm{Eu}-\mathrm{O}}^{\mathrm{B} 1}<\Delta E_{\mathrm{Eu}-\mathrm{O}}^{\mathrm{B} 2}$, which means that $\mathrm{Eu}^{3+}$ preferentially replaces $\mathrm{Ca} 2$ and Ca1. According to our calculation, $\mathrm{Eu}^{3+}$ preferentially occupies $\mathrm{Ca} 2$ and $\mathrm{Ca} 1$ sites, which is consistent with the environmental factor, the $\sigma\left(h_{\mathrm{e}_{i}}\right)$ analysis and PL spectrum.

\section{Conclusions}

The photoluminescence of $\mathrm{Ca}_{5}\left(\mathrm{BO}_{3}\right)_{3} \mathrm{~F}: 1 \% \mathrm{Eu}^{3+}$ shows that the excitation spectrum consists of some broadband from the $\mathrm{O}^{2-}$ $\rightarrow \mathrm{Eu}^{3+}$ charge transfer (CT) band and some sharp emission peaks derived from the $\mathrm{f}-\mathrm{f}$ transition of $\mathrm{Eu}^{3+}$. Two different $\mathrm{O}^{2-}$ $\rightarrow \mathrm{Eu}^{3+} \mathrm{CT}$ broad bands with the peaks at 266 and $283 \mathrm{~nm}$ in $\mathrm{Ca}_{5}\left(\mathrm{BO}_{3}\right)_{3} \mathrm{~F}: 1 \% \mathrm{Eu}^{3+}$ can be assigned to the $\mathrm{Eu}^{3+}$ sites occupying Ca1 and Ca2, respectively. Two ${ }^{5} \mathrm{D}_{0} \rightarrow{ }^{7} \mathrm{~F}_{0}$ peaks, $\mathrm{A}_{1}$ and $\mathrm{A}_{2}$, were found, which implies that $\mathrm{Eu}^{3+}$ doped in $\mathrm{Ca}_{5}\left(\mathrm{BO}_{3}\right)_{3} \mathrm{~F}$ has two sites. According to the dielectric theory of the crystal, the important chemical bonds such as the polarizability, the covalency and the environmental factor were quantitatively calculated. When $\mathrm{Eu}^{3+}$ ions occupy the $\mathrm{Ca} 1, \mathrm{Ca} 2$ and $\mathrm{Ca} 3$ sites of
$\mathrm{Ca}_{5}\left(\mathrm{BO}_{3}\right)_{3} \mathrm{~F}$, their environmental factors are $0.6397,0.7439$ and 0.3514 , respectively. The intensity ratio of ${ }^{5} \mathrm{D}_{0} \rightarrow{ }^{7} \mathrm{~F}_{2}$ transition to the $5 \mathrm{D}_{0} \rightarrow 7 \mathrm{~F}_{1}$ transition of $\mathrm{Eu}^{3+}$ at $\mathrm{Ca} 2$ (7.381) is 2.5 times stronger than that of $\mathrm{Eu}^{3+}$ at $\mathrm{Ca} 1$ site (2.933). The calculated ideal $\sigma\left(h_{\mathrm{e}_{i}}\right)$ showed that the $I\left({ }^{5} \mathrm{D}_{0} /{ }^{7} \mathrm{~F}_{2}\right) / I\left({ }^{5} \mathrm{D}_{0} /{ }^{7} \mathrm{~F}_{1}\right)$ value at Eu 1 is larger than that at Eu2 site. The local nonequivalence substitution distortion model was proposed to explain the result. The smaller deviation value of the bond energy method of $\Delta E_{\mathrm{Eu}-\mathrm{O}}^{\mathrm{Ca}}$ and $\Delta E_{\mathrm{Eu}-\mathrm{O}}^{\mathrm{Ca}}$ showed that the preferential sites of $\mathrm{Eu}^{3+}$ ion occupancy in $\mathrm{Ca}_{5}\left(\mathrm{BO}_{3}\right)_{3} \mathrm{~F}$ are $\mathrm{Ca} 2$ and $\mathrm{Ca} 1$. All of results are consistent with each other. The three theoretical methods provide us a new strategy to study the occupancy of $\mathrm{Eu}^{3+}$ in $\mathrm{Eu}^{3+}$ doped inorganic compounds.

\section{Conflicts of interest}

There are no conflicts to declare.

\section{Acknowledgements}

This work is financially supported by the National Natural Science Foundations of China (Grant no. 21301053 and 21571165) and Hubei Natural Science Foundations from Science and Technology Department of Hubei Province (2018CFB517).

\section{Notes and references}

1 D. Liu, Y. Jin, Y. Lv, G. Ju, C. Wang, L. Chen, W. Luo and Y. Hu, J. Am. Ceram. Soc., 2018, DOI: 10.1111/jace.15877, ahead of print.

2 H.-W. Wei, X.-M. Wang, H. Jiao and X.-P. Jing, J. Alloys Compd., 2017, 726, 22-29.

3 H. Xu, L. Wang, L. Tan, D. Wang, C. Wang and J. Shi, J. Am. Ceram. Soc., 2018, 101, 3414-3423.

4 R. Wei, L. Wang, F. Hu, X. Li, X. Peng, Y. Shi, H. Guo and J. Qiu, J. Lumin., 2018, 197, 291-296.

5 A. K. Pal, S. Som and C.-H. Lu, Ceram. Int., 2018, 44, 1825618263.

6 Y. Miao, K. Wang, L. Gao, B. Zhao, H. Wang, F. Zhu, B. Xu and D. Ma, J. Mater. Chem. C, 2018, 6, 8122-8134.

7 P. Chen, D. Yang, W. Hu, J. Zhang and Y. Wu, Chem. Phys. Lett., 2017, 689, 169-173.

8 Z. Xie, W. Zhou, W. Zhao, H. Zhang, Q. Hu and X. Xu, Chem. Phys. Lett., 2017, 685, 177-184.

9 T. S. Sreena, P. P. Rao, A. K. V. Raj and T. R. A. Thara, J. Alloys Compd., 2018, 751, 148-158.

10 G. Li, Y. Wei, W. Long and G. Xu, Mater. Res. Bull., 2017, 95, 86-94.

11 A. Kruopyte, R. Giraitis, R. Juskenas, D. Enseling, T. Justel and A. Katelnikovas, J. Lumin., 2017, 192, 520-526.

12 D. Kumar, B. P. Singh, M. Srivastava, A. Srivastava, P. singh, A. Srivastava and S. K. Srivastava, J. Lumin., 2018, 203, 507514.

13 K. Das, A. Marathe, X. Zhang, Z. Zhao and J. Chaudhuri, RSC Adv., 2016, 6, 95055-95061. 
14 A. Huang, Z. Yang, C. Yu, Z. Chai, J. Qiu and Z. Song, Mater. Lett., 2016, 185, 440-442.

15 P. Chen, F. Mo, A. Guan, R. Wang, G. Wang, S. Xia and L. Zhou, Appl. Radiat. Isot., 2016, 108, 148-153.

16 G. Chen, Y. Wu and P. Fu, J. Cryst. Growth, 2006, 292, 449453.

17 N. Kozhaya, M. Ferriol, M. Cochez, M. Aillerie and A. Maillard, Opt. Mater., 2011, 33, 1621-1625.

18 X. Li, P. Li, Z. Wang, S. Liu, Q. Bao, X. Meng, K. Qiu, Y. Li, Z. Li and Z. Yang, Chem. Mater., 2017, 29, 8792-8803.

19 L. Yi, J. Zhang, Z. Qiu, W. Zhou, L. Yu and S. Lian, RSC Adv., 2015, 5, 67125-67133.

20 L. Li, W. Wang, Y. Pan, Y. Zhu, X. Liu, H. M. Noh, B. K. Moon, B. C. Choi and J. H. Jeong, RSC Adv., 2018, 8, 1191-1202.

21 L. Li, J. Cao, B. Viana, S. Xu and M. Peng, Inorg. Chem., 2017, 56, 6499-6506.

22 W. Wang, Y. Pan, Y. Zhu, H. Xu, L. Zhou, X. Liu, L. Li, H. M. Noh and J. H. Jeong, Dalton Trans., 2018, 47, 65076518.

23 B. H. Toby, J. Appl. Crystallogr., 2001, 34, 210-213.

24 Y. Zhang, A. Abraha, R. Zhang, T. Shahbazyan, M. Fadavi, E. Heydari and Q. Dai, Opt. Mater., 2018, 84, 115-122.
25 W. You, Z. Xiao, F. Lai, X. Ye, C. Wang and H. Jiang, Zhongguo Xitu Xuebao, 2016, 34, 11-16.

26 M. Shi, C. Zhu, M. Lu, X. Meng and M. Wei, J. Am. Ceram. Soc., 2018, DOI: 10.1111/jace.15782, ahead of print.

27 J. B. Gruber, U. Vetter, T. Taniguchi, G. W. Burdick, H. Hofsaess, S. Chandra and D. K. Sardar, J. Appl. Phys., 2011, 110, 023104.

28 L. Zhou, J. Shi and M. Gong, J. Lumin., 2005, 113, 285-290.

29 P. A. Tanner, Y. Y. Yeung and L. Ning, J. Phys. Chem. A, 2013, 117, 2771-2781.

30 Y. Zhang, Q. Xiao, H. He, J. Zhang, G. Dong, J. Han and J. Qiu, J. Mater. Chem. C, 2015, 3, 10140-10145.

31 L. Li, X. Liu, H. M. Noh, S. H. Park, J. H. Jeong and K. H. Kim, J. Alloys Compd., 2015, 620, 324-328.

32 L. Li, Y. Pan, W. Wang, W. Zhang, Z. Wen, X. Leng, Q. Wang, L. Zhou, H. Xu, Q. Xia, L. Liu, H. Xiang and X. Liu, J. Alloys Compd., 2017, 726, 121-131.

33 Y. He and D. Xue, J. Phys. Chem. C, 2007, 111, 13238-13243. 34 L. Li, Y. Pan, W. Wang, Y. Zhu, W. Zhang, H. Xu, L. Zhou and X. Liu, J. Alloys Compd., 2018, 731, 496-503. 